\title{
Viral infections in lung transplantation
}

\author{
Aline Munting ${ }^{1}$, Oriol Manuel ${ }^{1,2}$ \\ ${ }^{1}$ Infectious Diseases Service, Lausanne University Hospital, Lausanne, Switzerland; ${ }^{2}$ Transplantation Center, Lausanne University Hospital, \\ Lausanne, Switzerland \\ Contributions: (I) Conception and design: None; (II) Administrative support: None; (III) Provision of study materials or patients: None; (IV) \\ Collection and assembly of data: None; (V) Data analysis and interpretation: None; (VI) Manuscript writing: Both authors; (VII) Final approval of \\ manuscript: Both authors. \\ Correspondence to: Oriol Manuel, MD. Infectious Diseases Service and Transplantation Center, Lausanne University Hospital (CHUV), BH 10-549. \\ Bugnon 46, 1011 Lausanne, Switzerland. Email: oriol.manuel@chuv.ch.
}

\begin{abstract}
Viral infections account for up to 30\% of all infectious complications in lung transplant recipients, remaining a significant cause of morbidity and even mortality. Impact of viral infections is not only due to the direct effects of viral replication, but also to immunologically-mediated lung injury that may lead to acute rejection and chronic lung allograft dysfunction. This has particularly been seen in infections caused by herpesviruses and respiratory viruses. The implementation of universal preventive measures against cytomegalovirus (CMV) and influenza (by means of antiviral prophylaxis and vaccination, respectively) and administration of early antiviral treatment have reduced the burden of these diseases and potentially their role in affecting allograft outcomes. New antivirals against CMV for prophylaxis and for treatment of antiviral-resistant CMV infection are currently being evaluated in transplant recipients, and may continue to improve the management of CMV in lung transplant recipients. However, new therapeutic and preventive strategies are highly needed for other viruses such as respiratory syncytial virus (RSV) or parainfluenza virus (PIV), including new antivirals and vaccines. This is particularly important in the advent of the COVID-19 pandemic, for which several unanswered questions remain, in particular on the best antiviral and immunomodulatory regimen for decreasing mortality specifically in lung transplant recipients. In conclusion, the appropriate management of viral complications after transplantation remain an essential step to continue improving survival and quality of life of lung transplant recipients.
\end{abstract}

Keywords: Immunomodulatory effects; herpesvirus; respiratory viral infections; chronic lung allograft dysfunction (CLAD); antiviral drugs

Submitted Mar 15, 2021. Accepted for publication Jun 21, 2021.

doi: $10.21037 /$ jtd-2021-24

View this article at: https://dx.doi.org/10.21037/jtd-2021-24

\section{Introduction}

Lung transplant recipients are considered to be at the highest risk for infectious complications among all solidorgan transplant (SOT) recipients. This increased risk is due to some particularities of lung transplantation, including a direct contact of the organ with the environment (that may more commonly expose allograft to external pathogens) and an overall more important net state of immunosuppression due to higher doses of immunosuppressive drugs needed to prevent acute rejection. In patients with cystic fibrosis, a higher rate of pre transplant colonisation with multidrug resistant pathogens is observed, that may increase the risk for post-transplant surgical site infection or pneumonia caused by these pathogens $(1,2)$. Post-transplant infections have been more robustly associated with impaired transplant outcomes in lung transplant recipients than in other transplant recipients, namely a higher risk for acute allograft rejection (3), chronic lung allograft dysfunction (CLAD) $(4,5)$ and/or decreased survival.

Recent cohort studies provide updated and comprehensive data on the epidemiology of infectious complications in lung 


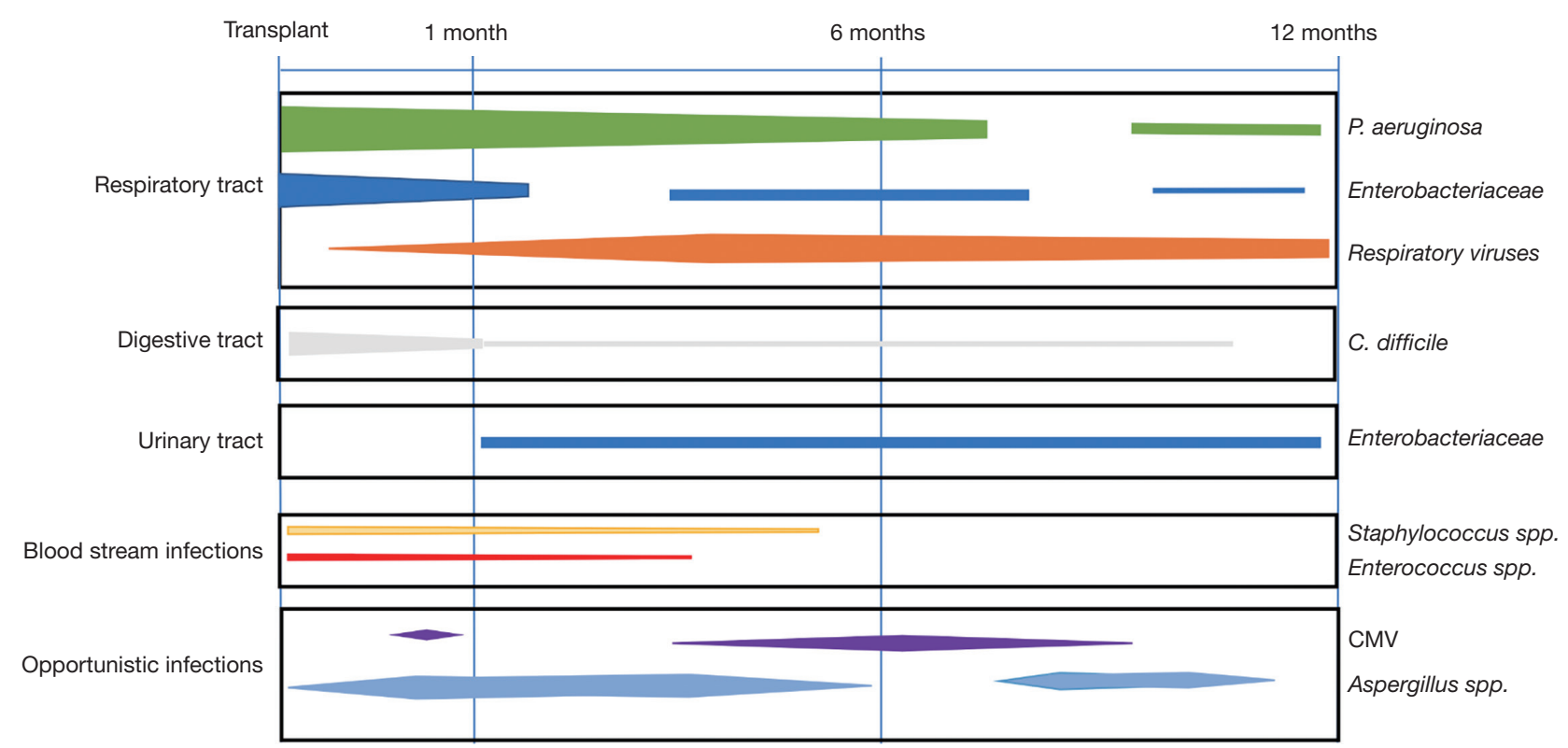

Figure 1 Timeline and burden of infection in lung transplant recipients in the Swiss Transplant Cohort Study (2). The timeline and relative burden are based on the temporal distribution of 463 episodes of infection in 286 lung transplant recipients. CMV, cytomegalovirus.

transplant recipients. In a Swiss nationwide cohort of SOT recipients including more than 3,500 patients, the rate of clinically significant infection was higher in lung transplant recipients as compared to all other organs (1.7 infections vs. 1.3 infections per person-year in all SOT recipients). In lung transplant recipients, approximately $60 \%$ of all infections were caused by bacteria, while viral infections represented $30 \%$ of them. In this cohort, the most common viral pathogens were respiratory viruses [mainly picornaviruses, influenza, and respiratory syncytial virus (RSV)] and herpesviruses [including cytomegalovirus (CMV), herpes simplex virus (HSV), and varicella-zoster virus (VZV)] (Figure 1) (2). Current antivirals used for treating respiratory viral and herpesvirus infections are summarized in Table 1 and Table 2, respectively.

In this review, we will update the epidemiology, clinical manifestations, management and outcomes of the most common viral infections that have a significant impact on lung transplantation, focusing on respiratory viral and herpesvirus infections. We will not address in the present review the topic of viral hepatitis.

\section{Respiratory viral infections}

\section{General considerations}

Respiratory viruses are increasingly recognized as a major cause of morbidity and mortality in SOT recipients, and particularly in lung transplant recipients. Viral pathogens of particular clinical relevance include influenza A and $B$ viruses, RSV, parainfluenza virus (PIV), human metapneumovirus (hMPV), human coronaviruses ( $\mathrm{HCoV}$ ), picornaviruses, and adenovirus $(1,3)$. A novel $\mathrm{HCoV}$ named SARS-CoV-2 was identified in the Chinese province of Wuhan in late 2019 and has caused a pandemic of a respiratory and multisystemic disease named COVID-19 (6). COVID-19 seems to have a more severe course in lung transplant recipients than in the general population (7-9).

Seasonal patterns of respiratory viral infections in lung transplant recipients are similar as those found in the community, with a higher incidence rate during winter (10-13). Prevalence of respiratory viral infections varies between studies mostly due to the type of screening done, with usually a higher incidence in prospective cohorts using a universal screening including asymptomatic patients, and lower incidence in retrospective studies. Although clinical manifestations are generally not associated with a specific respiratory virus, in a cohort from Spain half of upper respiratory tract infections were caused by picornavirus (rhinovirus), whereas RSV, PIV, hMPV and influenza mainly caused pneumonia. Asymptomatic infections were associated largely with picornavirus (10). Of note, clinical manifestations of respiratory viral infections in 
Table 1 Antiviral drugs used for therapy of respiratory viral infections in lung transplant recipients

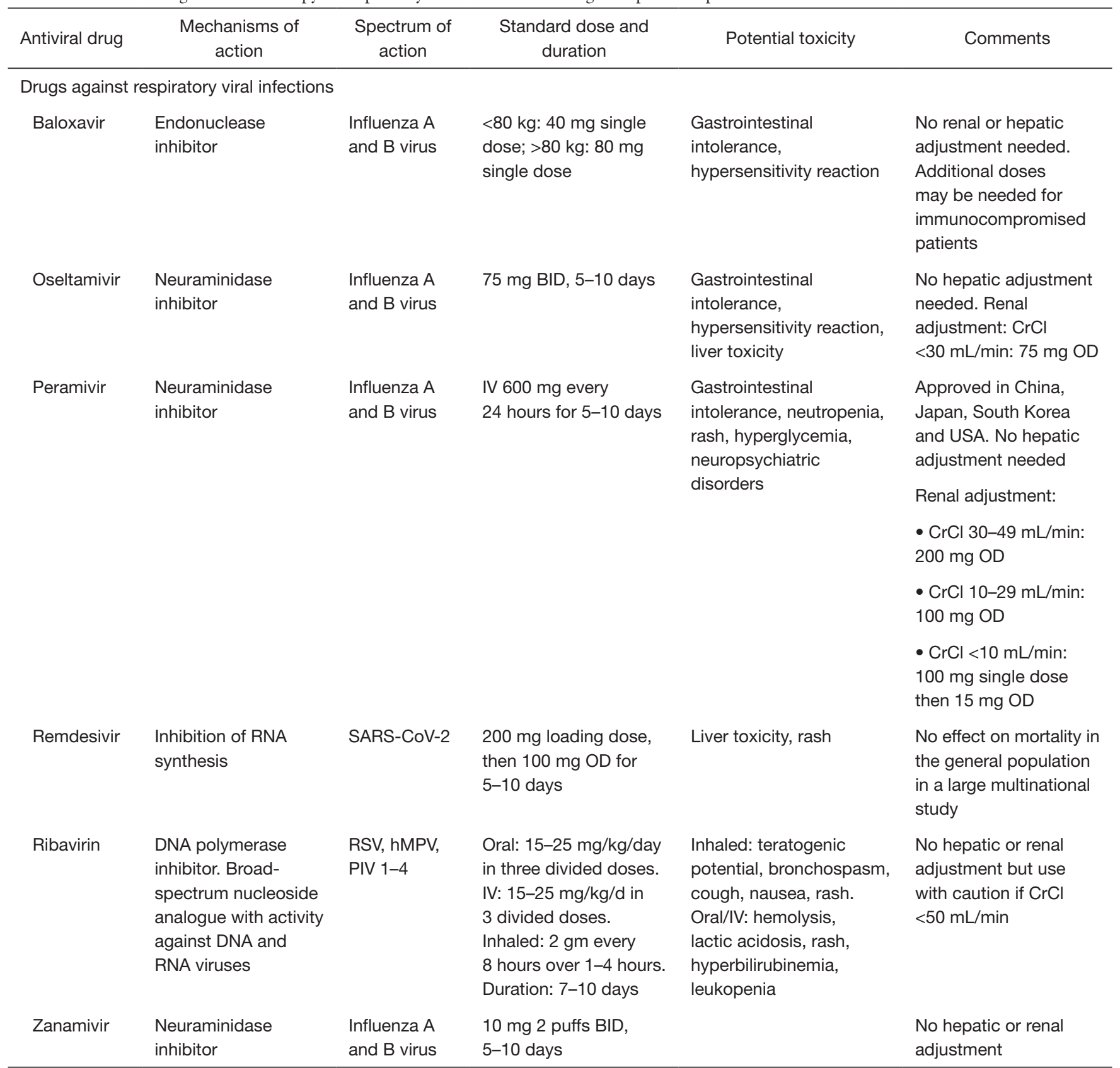

$\mathrm{BID}$, twice daily; $\mathrm{CrCl}$, creatinine clearance; hMPV, human metapneumovirus; OD, once daily; PIV, parainfluenza virus; RSV, respiratory syncytial virus; SARS-CoV-2, severe acute respiratory syndrome-coronavirus-2; TID, thrice daily; TIW, thrice weekly.

lung transplant recipients can be mild or atypical and may initially presented as shortness of breath or subtle changes in pulmonary function without frank symptoms (14). Due to immunosuppression and altered respiratory mucociliary clearance in the first months after surgery, progression to bronchiolitis and pneumonia can be high after lung transplantation, with an incidence up to $25 \%$ (15). Respiratory viral infections seem also to be a risk factor for secondary bacterial or fungal pneumonia $(10,16)$.

In lung transplant recipients, respiratory viral infections may cause inflammatory processes mediated by both the innate and the adaptive immune responses (5). In addition 


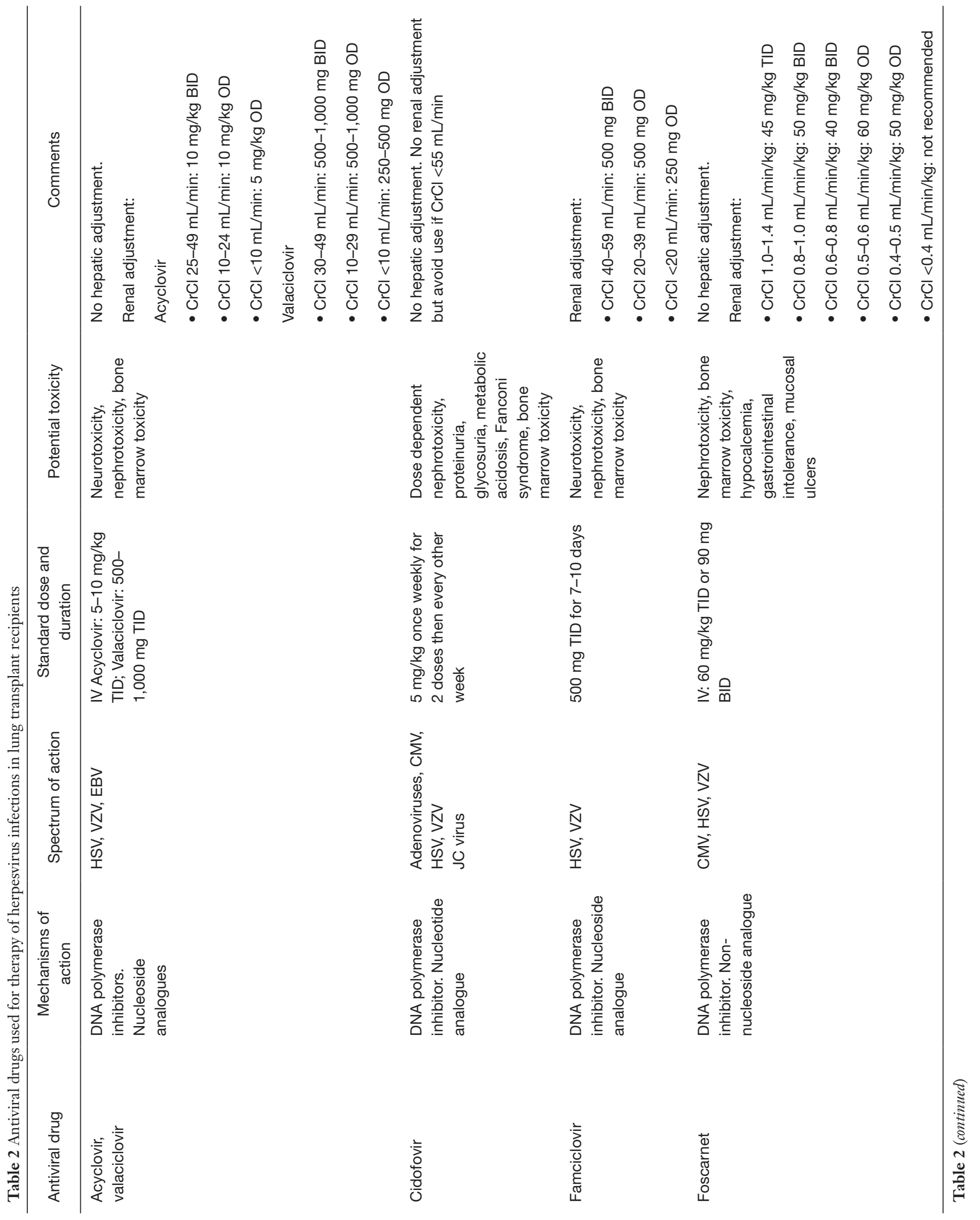




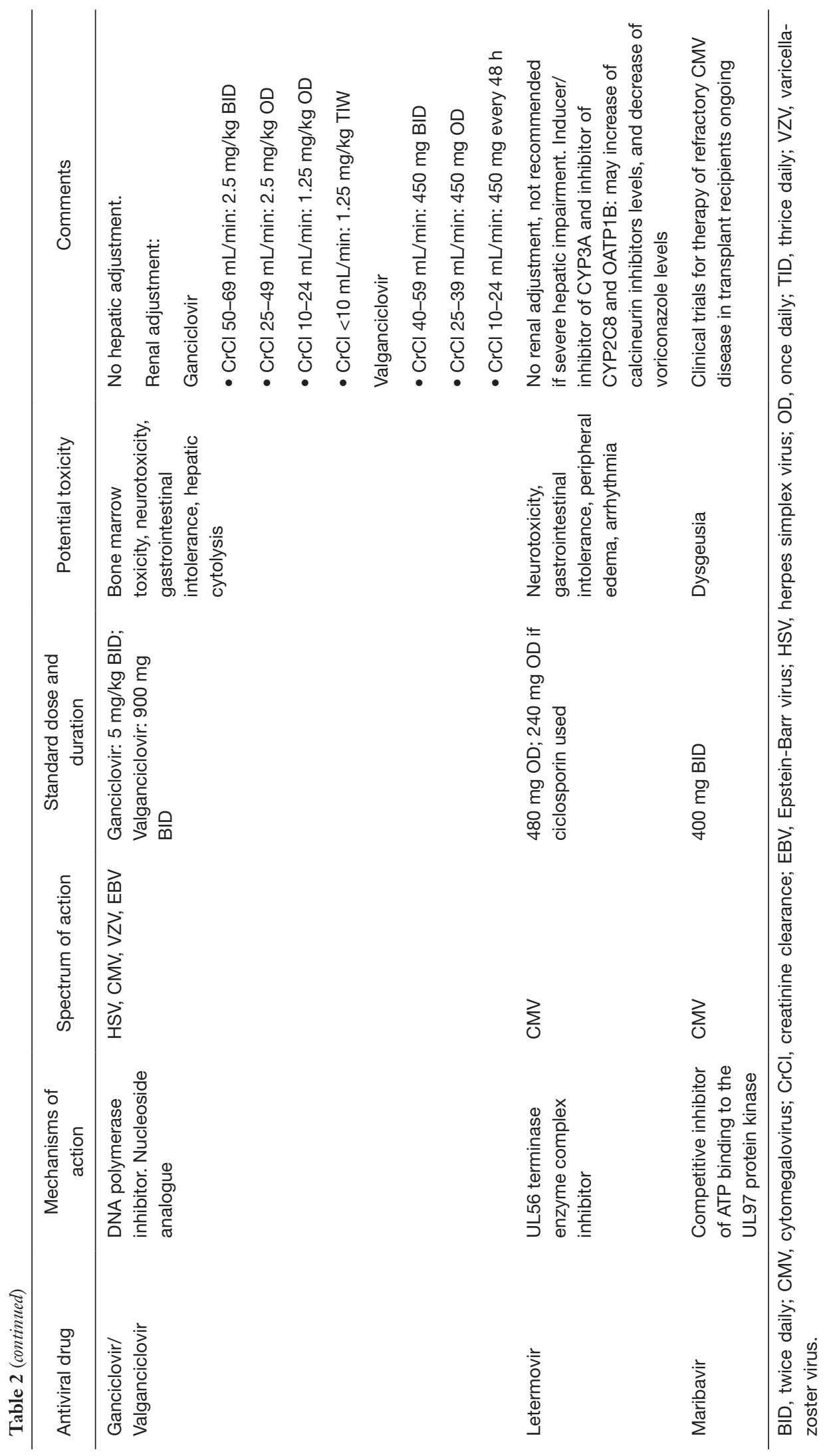


to the direct sequelae and tissue damage, respiratory viruses may promote immunologically-mediated lung injury resulting in the development of acute rejection and $\operatorname{CLAD}(3,5)$. CLAD is a multifactorial process that leads to progressive and irreversible decline in allograft function, with a reported 5 -year incidence of up to $50 \%(17,18)$. CLAD is the leading cause of mortality after the first year post-transplant, accounting for $20-30 \%$ of deaths (19). Recent reports including large cohorts using multiplex panels support the association between respiratory viral infections and CLAD (1,10,20-22). Peghin et al. reported in a prospective study in Spain using universal screening that respiratory viral infections were associated with the development of CLAD, with a hazard ratio (HR) of 3.0 $(\mathrm{P}=0.002)$ (20). Likewise, in a study including 250 lung transplant patients who underwent symptom-guided testing for respiratory viral infections, an independent association with CLAD was observed in multivariate models ( $\mathrm{HR}=1.9$; $\mathrm{P}=0.03$ ) (22). Finally, Allyn et al. found that patients with viral pneumonia had an increased risk of CLAD (HR=3.94, $\mathrm{P}<0.01)(21)$. Taken together, it seems that the association between respiratory viral infections and the development CLAD is more robust in case of symptomatic viral infection (20-22). For example, in the Spanish cohort, asymptomatic respiratory viral infections were not associated with a significant decline in lung function (10). Importantly, although studies suggested that some viruses (RSV and influenza) were more commonly responsible for the development of CLAD, more recent data using multiplex panels have not associated a particular virus with CLAD (23-29). This supports the hypothesis of an increased immunologic activation in the allograft, rather than specific viral virulence factors $(20,30)$. More evidence is needed to understand if viral infection is only a marker of patients at risk or the actual cause of CLAD (22).

\section{Influenza viruses}

Influenza viruses belong to the Orthomyxoviridae family, with two main genera causing yearly worldwide epidemics: influenza A virus (with two main circulating subtypes $\mathrm{A} / \mathrm{H} 1 \mathrm{~N} 1$ and $\mathrm{A} / \mathrm{H} 3 \mathrm{~N} 2$ ), and influenza $\mathrm{B}$ virus (with currently two subtypes, Yamagata and Victoria). Influenza is associated with significant morbidity and mortality in immunocompromised patients. In a study evaluating the clinical outcomes of more than 35,000 patients with influenza, immunosuppression was strongly associated with more severe complications including the need for
ICU admission, mechanical ventilation, and death (31). In SOT recipients, lung transplant patients have the highest incidence of influenza, with a reported rate of 41.8 cases per 1,000 persons-year (as compared to 4.3 cases per 1,000 persons-year in kidney transplant recipients) (32). Influenza transmission from donor to recipient has been documented in lung transplant recipients (33).

The clinical presentation of influenza in lung transplant recipients is similar than in the general population, with cough and coryza as symptoms commonly found, although fever can be absent in up to $40 \%$ of patients, and non-respiratory symptoms are frequently reported (myalgia, headache, and gastro-intestinal symptoms) (34). Asymptomatic influenza seems to be uncommon in lung transplant recipients $(3,10,13)$.

Diagnosis of influenza relies in the identification of influenza virus in nasopharyngeal swab or other respiratory sample. Of note, the most accurate assay is nucleid acid testing (NAT), which has replaced other assays using antigen identification. Rapid NAT assays have the advantage of diagnosis in 2-3 hours, and therefore may foster the administration of early antiviral therapy $(34,35)$.

Therapy of influenza is based on the administration of a neuraminidase inhibitor (NAI). Currently approved NAI are oral oseltamivir, inhaled zanamivir, and intravenous peramivir. In large observational cohort studies, early administration of oseltamivir in SOT recipients showed a decreased rate of pneumonia, ICU admission, and allograft dysfunction (34-36). Because these benefits seems to remain even if the drug is given after the first 48 hours of symptoms and because immunocompromised patients have prolonged viral shedding, therapy for influenza is recommended irrespective of the duration of symptoms $(35,37)$. Resistance to oseltamivir is mostly seen with influenza $\mathrm{A} / \mathrm{H} 1 \mathrm{~N} 1$ and accounts for $0.5-3.4 \%$ of circulating strains $(38,39)$. Lung transplant recipients are considered at higher risk of developing resistance because of potential higher viral loads and prolonged shedding during infection (37). The most common mutation identified is $\mathrm{H} 275 \mathrm{Y}$ mutation in influenza $\mathrm{A} / \mathrm{H} 1 \mathrm{~N} 1$, which confers resistance to oseltamivir and peramivir, but does not affect the activity of zanamivir (39). Oral baloxavir marboxil is a novel antiviral with a mechanism of action relying on the selective inhibition of the influenza cap-endonuclease, which has shown similar efficacy than oseltamivir for prevention and therapy of uncomplicated influenza in the general population (40). Of note, up to $10 \%$ of patients developed a resistance to baloxavir due to the low genetic barrier (41). 
Despite absence of experience on the use of baloxavir in lung transplant recipients, combined therapy of oseltamivir and baloxavir could be considered in case of suspicion of NAI resistance or in high-risk patients very early after transplantation.

Patients with influenza in healthcare facilities need to be isolated with standard and droplets measures. Nosocomial transmission of influenza is underestimated and remains a real concern because of high rates of morbidity and mortality documented in immunocompromised patients (42). The main preventive strategy against influenza remains the administration of the seasonal trivalent or quadrivalent inactivated influenza vaccine. Vaccination in lung transplant recipients is highly recommended as it reduces the incidence of influenza and prevents the development of severe clinical presentations, such as pneumonia and ICU admission $(4,43,44)$. Different strategies to increase immunogenicity of the vaccine in SOT recipients are currently evaluated, using high-dose or adjuvanted vaccines (45-47). Current guidelines recommend annual influenza vaccination to all transplant candidates and recipients and to their closed family and contacts (48). Oral oseltamivir can be an alternative for prevention in patients at risk of severe influenza if poor immunogenicity of the vaccine is expected.

\section{RSV}

RSV is a paramyxovirus belonging to the Pneumovirus genus, which causes annual epidemics worldwide, particularly in young children. RSV is a leading cause of respiratory tract infections in lung transplant recipients and has been associated with impaired allograft outcomes. Mortality rates of $10 \%$ to $20 \%$ despite medical treatment and supportive care have been reported (49-52); although recent data suggest that attributable mortality is much lower (53). There is no strong evidence on the best therapy for RSV in lung transplant recipients $(26,49,54)$. Uncontrolled data suggest that inhaled or oral ribavirin (with or without addition of IVIG or steroids) is associated with a decreased rate of progression from upper to lower respiratory infections (55). Presatovir, a novel orally RSV fusion inhibitor, has failed to improve viral or clinical outcomes in lung and stem cell transplant recipients $(56,57)$. Beside general preventive measures and isolation of RSV cases, there is no validated preventive strategy against RSV in adult SOT recipient; in children younger than 24 months, the RSV-specific humanized monoclonal antibody palivizumab may be considered for prophylaxis.

\section{PIVs}

PIVs are enveloped RNA viruses from the genus Paramyxoviridae, with four types known (PIV-1 to 4). Most of PIV infections are community-acquired, but outbreaks have been described in health care facilities (58). PIV usually cause mild upper respiratory infections, but can lead to severe lower respiratory tract infections in lung transplant patients. PIV infections are also associated with allograft lung dysfunction $(3,15)$. Treatment is mainly based on supportive care and reduction of immunosuppression, although some experts recommend the use of ribavirin and IVIG to treat severe PIV infections. A novel recombinant sialidase fusion protein administered by oral inhalation, DAS181, has shown a good response in two reports in lung transplant recipients and a phase 2 trial is currently ongoing for the treatment of PIV in transplant recipients (59-61).

\section{bMPV}

$\mathrm{hMPV}$ is an RNA paramyxovirus that causes respiratory infections with clinical manifestations similar than in patients with RSV infection. hMPV infection is common in lung transplant recipients and can cause severe presentation with pneumonia, acute and chronic allograft dysfunction (44). Ribavirin with or without IVIG may be considered for therapy in case of severe infection, but supportive care remains the main treatment for hMPV infection (62).

\section{Picornaviruses}

Human rhinovirus and enteroviruses are members of the Picornaviridae family. Because current molecular diagnostic assays usually do not differentiate between both genera, the term picornavirus infection is preferred, although most of the upper respiratory viral infections found in lung transplant recipients are actually caused by rhinoviruses (10). Infections are usually mild, with cough and rhinorrhea being the most common symptoms, although lower respiratory tract infections in lung transplant recipients have also been described $(10,13)$. Of note, in case of universal screening by PCR, up to one third of rhinovirus infection in lung transplant recipients may be asymptomatic. Rhinovirus can also cause chronic infection with protracted viral shedding and progressive decline in lung function (63). There is no 
specific treatment or prophylaxis for rhinovirus infection.

\section{$\mathrm{HCoV}$}

HCoV, including HCov 229E, NL63, OC43, and HKU1, are a frequent cause of respiratory viral infection in lung transplant recipients (13). $\mathrm{HCoV}$ usually causes mild upper respiratory disease but may progress to low respiratory tract infections. Two additional zoonotic $\mathrm{HCoV}$ were associated with outbreaks of severe respiratory syndrome in the last decade, namely SARS-CoV and MERS-CoV, with very few cases diagnosed in SOT recipients (64). A novel coronavirus disease caused by SARS-CoV-2, named COVID-19, was first described in December 2019 in Wuhan, China, and declared as pandemic in March 2020, affecting millions of people worldwide (6). In the general population, approximately $20 \%$ of patients with COVID-19 have a moderate to severe presentation that requires hospitalization, and $5 \%$ progress to critical disease, with a mortality estimated between $1-3 \%$ (65). The clinical course of COVID-19 is characterized by a first phase of viral syndrome with fever and cough, with high SARS-CoV-2 viral load found in the respiratory tract, followed by a second inflammatory phase associated with the development of ARDS and a hypercoagulability state, due to massive cytokine release (66). Currently, it is under discussion whether COVID-19 have a more severe course in SOT recipients than among general population (67-69). On the one hand, SOT recipients are known to have a higher risk for complications of respiratory viral infections. On the other hand, the immunosuppressive regimens used after transplantation may attenuate the manifestations of the inflammatory syndrome produced by SARS-CoV-2 infection. Assessment of mortality is challenging because of potential diagnostic biases towards more severe cases, a higher rate of comorbidities in transplant recipients as compared to the general population, and differences in overall mortality among centers. Nevertheless, recent reports showed a higher mortality among hospitalized transplant recipients compared to general population when adjusting for comorbidities. In a French study comparing outcomes between matched kidney transplant recipients and non-transplant patients, the 30-day cumulative incidence of severe SARS-CoV-2 infections did not differ between the two groups, whereas 30-day mortality was significantly higher in kidney transplant recipients $(17.9 \%$ vs. $11.4 \%$ respectively, $\mathrm{P}=0.038$ ). Specifically for lung transplant recipients, a large international cohort involving 482 SOT recipients, with only 30 cases of lung transplant recipients, showed a mortality of $20.5 \%$ in the whole cohort and $33 \%$ among lung transplant recipients (9). In a French cohort including 35 lung transplant recipients most patients had a severe presentation and requiring hospitalization, resulting in $14.2 \%$ of hospital mortality (69).

No clinical trials are available evaluating COVID-19 treatment specifically among SOT recipients. As a consequence, evidence to guide their management is draw from large clinical trials among general population. In the UK Recovery trial, dexamethasone reduced mortality in patients who needed oxygen or invasive ventilation (70), and has become the standard of care for COVID-19 also in lung transplant recipients. Addition of tocilizumab, an anti-IL6 receptor, may further improve patient outcomes, in particular at the time of admission in the ICU (71). However, the potential increased risk of opportunistic infections in lung transplant recipients with the use of these immunomodulatory drugs has not been systematically evaluated, so that caution is needed with its use. Remdesivir reduced the time to recovery and length of stay in one US trial (72), but did not showed a significant decrease in need for ICU, length of stay and mortality in a large multinational trial including more than 10,000 patients (73), so that the use of remdesivir is not universally recommended for treating COVID-19 in the general population (74). Convalescent plasma and use of anti-Spike monoclonal antibodies seems to improve outcome by reducing viral load and rate of severe outcomes when given very early in the course of infection, before the development of the cytokine storm (75-77). Although very few data are available specifically in lung transplant recipients, these therapies could be used for preventing severe COVID-19 at the time of the initial diagnosis. Modulation of immunosuppression during COVID-19 is an important part of the therapeutic approach of COVID-19 in SOT recipients $(9,78)$. Based on expert opinion, it is recommended to taper or discontinue temporarily antimetabolites, but to maintain calcineurin inhibitors and corticosteroids (7,79-81). International scientific societies advice against the use of organs from deceased donors tested positive for SARS-CoV-2, particularly for lung donors (81-83). However, a case report describing a proven transmission of SARS-CoV-2 from a lung donor, who tested negative by RT-PCR on a nasopharyngeal swab but positive on bronchoalveolar lavage fluid when subsequently tested, supports universal SARS$\mathrm{CoV}-2$ testing in the lower respiratory tract before lung donation (84).

Recent data showed that immunogenicity of mRNA 
vaccines against SARS-CoV-2 is highly impacted in solid organ transplantation, as compared to the general population, with only $30-50 \%$ of transplant recipients able to generate an antibody response after 2 doses of vaccine, suggesting that most transplant recipient remain at risk for SARS-CoV-2 infection after vaccination $(85,86)$. Use of antimetabolites, in particular mycophenolate, seem to be associated with impaired responses. Interventional research is needed to establish additional strategies for increasing the immunogenicity of COVID-19 vaccines specifically in SOT recipients.

\section{Adenoviruses}

Adenovirus is a non-enveloped double-stranded DNA virus of the family Adenoviridae. Infections due to adenovirus occur throughout the year without seasonality (87). Clinical presentation cannot be differentiated from other respiratory viral infections, usually causing mild upper respiratory tract infection (62). However, in highly immunosuppressed patients, life threatening disseminated disease with viremia and organ failure can also be seen. Treatment of adenoviral infection is supportive with reduction of immunosuppression therapy (88). Cidofovir and brincidofovir can be used in case of disseminated disease $(27,89,90)$.

\section{Herpesviruses infections}

\section{CMV}

CMV is a ubiquitous $\beta$-herpesvirus that persists as a latent virus after primary infection and can reactivate in immunocompromised individuals $(91,92)$. CMV infection is defined as the presence of CMV replication in tissue, blood, or other body fluids regardless of symptomatology (93). CMV disease refers to CMV infection with clinical signs and symptoms and can be categorized as CMV syndrome (presenting with fever, malaise, leukopenia, thrombocytopenia, and/or elevated hepatic transaminases) and end-organ CMV disease (colitis, gastritis, pneumonitis, hepatitis, retinitis) (94). The presence of CMV in a biopsy is needed for the diagnostic of proven disease (except for CMV retinitis); otherwise, the event is referred as probable disease (95).

The main risk factor for the development of CMV disease is CMV serostatus of the donor (D) and recipient (R), being $\mathrm{D}_{+} / \mathrm{R}-$ patients at the highest risk and CMVseropositive recipients $(\mathrm{R}+)$ at a moderate risk $(93,96,97)$.
Immunosuppression plays also a role, with the use of lymphocytes-depleting agents associated with increased risk $(98,99)$, and the use of mTOR inhibitors generally associated with a lower risk (100).

The most common clinical manifestations of CMV disease in lung transplant recipients include viral syndrome and gastrointestinal disease (colitis and gastritis). While CMV pneumonitis was an important complication in the early years of lung transplantation, the incidence of CMV pneumonitis in lung transplant recipients nowadays is relatively low (less than 10\%). However, given that CMV replication in the allograft measured in the bronchoalveolar lavage is relatively common (40-45\%), diagnosis of CMV pneumonitis may be challenging in this setting. In addition to the direct effects of CMV infection and disease, CMV has pro-inflammatory and immunosuppressive effects (101-103). In lung transplant recipients, CMV has been associated with CLAD in some, but not all studies (104-107). Those immunomodulatory effects of CMV may predispose patients to opportunistic infections, in particular fungal infections $(101,108,109)$. The use of universal antiviral prophylaxis in the current era seems to reduce the impact of CMV in allograft outcomes $(110,111)$.

Without a preventive strategy, CMV infection and disease typically occur during the first three months after transplantation (93). Current incidence of CMV disease in lung transplant recipients varies from $5 \%$ to $40 \%$ depending on serological status and preventive strategy used (111-113). The main preventive strategies against CMV disease are antiviral prophylaxis and preemptive approach. Antiviral prophylaxis consists in the administration of an antiviral drug for a defined period, generally 6 to 12 months in lung transplant recipients. The pre-emptive approach is based on monitoring of CMV viral load in blood/plasma and administrating an antiviral drug in case of early detection of CMV replication before the development of symptoms. While the preemptive approach is widely used in kidney and liver transplant recipients, antiviral prophylaxis with valganciclovir remains the most commonly used preventive strategy in lung transplant recipients, in both $\mathrm{D}+/ \mathrm{R}-$ and $\mathrm{R}+$ patients (93). Potential advantages of prophylaxis include a better control of CMV replication early after transplant, which may reduce the immunomodulatory effects of CMV. However, antiviral prophylaxis may also delay the mounting of an effective cell-mediated immunity to control CMV replication. Of note, no controlled trial has compared both strategies after lung transplantation (108,112,114-117). Letermovir is a novel antiviral drug targeting UL56 of the 
terminase enzyme complex approved for CMV prophylaxis in stem cell transplantation (118-120). Experience in lung transplant recipients is limited to case reports of secondary antiviral prophylaxis after ganciclovir-resistant cases $(121,122)$. A phase III trial is ongoing comparing valganciclovir and letermovir for CMV prophylaxis in kidney transplant recipients.

Recent data suggest that the assessment of cell-mediated immunity may better predict the risk for developing CMV disease post transplant that CMV serostatus, so that the use of a routine $\mathrm{CMV}$ immune monitoring strategy can help to individualize prevention of CMV in a given patient (123). In a recent randomized trial involving 118 lung transplant recipients, patients were randomized to receive either 5 months of prophylaxis or a variable duration according to the result of the Quantiferon-CMV (an assay measuring the release of interferon- $\gamma$ after stimulation by CMV antigens) (124). Patients in the intervention arm had a lower incidence of CMV replication in the allograft, in particular those patients with a detectable cell-mediated immunity. Other trials to adapt the duration of prophylaxis in different transplant settings are ongoing (123).

Therapy of CMV disease generally consists on the administration of oral valganciclovir or IV ganciclovir (125). Duration of therapy is usually 3 to 4 weeks, and it is determined by a clinical response and reduction in CMV viremia. Secondary prophylaxis for 4-6 additional weeks with valganciclovir is usually recommended to avoid early relapse, particularly in $\mathrm{D}+/ \mathrm{R}-$ patients. Recently, a noncontrolled trial showed that patients with detectable cellmediated immunity at the end of antiviral therapy had a low risk for relapse, and that secondary prophylaxis was not needed in these patients (126). Antiviral-resistant CMV remains an important clinical concern in $\mathrm{D}+/ \mathrm{R}-$ lung transplant recipients, with an estimated incidence of $5-15 \%$ (127-129). The most common mechanisms of resistance are mutations in the UL97 kinase and in the UL54 DNA polymerase (130-132). Antiviral resistance should be suspected in case of increased viral load or persistent clinical symptoms despite adequate antiviral treatment for two weeks (117). Treatment of drug-resistant CMV is largely based on expert opinion, but foscarnet or cidofovir and reduction in immunosuppression remain the preferred strategy (93). Maribavir is a competitive inhibitor of ATP binding to the UL97 protein kinase of CMV (133). A randomized phase II study in patients with refractory $\mathrm{CMV}$ infection showed resolution of CMV viremia in two-thirds of patients within 6 weeks of maribavir treatment (133), and a phase III trial has recently been completed and results are expected soon.

\section{Epstein-Barr virus (EBV)}

EBV is a ubiquitous gamma-herpesvirus with a seroprevalence reaching $90-95 \%$ of the adult population. Primary infection occurs mainly in children and young adults and can be asymptomatic or present as a febrile syndrome known as infectious mononucleosis. EBV has a tropism for B-cell lymphocytes with the ability to remain latent throughout life. In transplant recipients, the lack of cell-mediated immune surveillance due to immunosuppression can lead to uncontrolled proliferation of EBV infected B-cells (134). This entity is known as post transplant lymphoproliferative disorder (PTLD) $(135,136)$, which is the most common malignancy complicating solidorgan transplantation, after skin cancer (137). The highest risk for EBV-related PTLD is seen in seronegative patients who receive an allograft from a seropositive donor (D+/R-), a particular concern in pediatric transplantation $(138,139)$. Due to a higher net state of immunosuppression, PTLD is more common in lung transplant recipients $(140,141)$, with a cumulative incidence within 5 years ranging from $3.4 \%$ to $9.4 \%$, as compared to $0.5 \%$ to $1 \%$ in other SOT recipients (142-146).

The clinical presentation of PTLD is heterogeneous, ranging from localized lesions to disseminated disease, and it is characterized by high incidence of extranodal involvement, including frequently the gastro-intestinal tract (in $20-30 \%$ of cases), allograft (10-15\% of cases), and central nervous system (CNS) (5-20\% of cases) (146-149).

Prevention of PTLD in high-risk lung transplant recipients is of major importance. Although antiviral drugs (acyclovir or ganciclovir) have in vitro activity against EBV, they act only in lytic virus and not on the latently EBVinfected cells, so that the efficacy of antiviral prophylaxis for preventing EBV primary infection remains unknown. However, given the wide antiviral activity of ganciclovir against the other herpesviruses, it is widely used in this setting. Another preventive strategy for PTLD in highrisk patients is a preemptive approach consisting on the monitoring of peripheral blood EBV DNA levels (150-153), to identify patients with persistent high-levels of EBV DNAemia at higher risk for the development of PTLD $(154,155)$. These patients may theoretically benefit from an intervention to decrease the level of EBV DNAemia, such as reduction of immunosuppressive therapy or 
administration of rituximab, a monoclonal anti-CD20 antibody. Despite limited published data, this preemptive strategy seems to be able to reduce the incidence of PTLD among pediatric SOT recipients $(156,157)$. Limitations of this approach include a low predictive value of the detection of EBV DNAemia for subsequent EBV-related PTLD, the lack of EBV assay standardization, and the absence of a defined optimal monitoring algorithm (147).

The initial management of PTLD consists in a careful reduction of immunosuppression to restore partially the T-cell immunity (136). This strategy alone leads to a regression of polyclonal PTLD in $20-80 \%$ of cases $(136,155)$. Rituximab associated or not with chemotherapy (CHOP) is the standard treatment in patients who do not have a response to reduced immunosuppression (158). Surgery, radiotherapy and adoptive immunotherapy $(159,160)$ are used in case of non-response of the first-line strategies (147).

\section{$H S V$}

HSV-1 and HSV-2 belong to the alphaherpesvirinae subfamily and have the particularity to remain latent in the sensitive nerve root ganglia after primary infection $(161,162)$. While HSV-1 is transmitted by oral secretions and HSV-2 by sexual contacts, both viruses can be found in either location. HSV disease in adult SOT patients is mainly due to reactivation, although donor transmission in seronegative patients has been documented (163). Seroprevalence in SOT recipients follows that of the general population and it ranges from $70-80 \%$ for HSV1 and $10-20 \%$ for HSV-2 (164). Mucocutaneous disease with painful blisters or ulcers at the site of infection is the most common clinical presentation of HSV disease in lung transplant recipients, and it can be more severe than in immunocompetent individuals, with disseminated cutaneous disease and visceral involvement (up to $15 \%$ in recent series of SOT recipients) $(2,164,165)$. In absence of prophylaxis, up to $25-35 \%$ of patients will reactivate HSV, particularly in the first weeks following transplantation (166). However, in the era of antiviral prophylaxis, incidence is substantially lower. For example, in a recent cohort study the incidence of HSV infection at 1-year post transplant was only $1.8 \%$ in lung transplant recipients, as compared to $9.4 \%$ heart transplant recipients, a difference explained by the longer duration of CMV prophylaxis in lung transplant recipients (164). Specific HSV prophylaxis with acyclovir, valaciclovir, or famciclovir is recommended for lung transplant recipients not receiving otherwise CMV prophylaxis (CMV D-/R- patients or patients followed by a preemptive approach) (Figure 2). Therapy of established $\mathrm{HSV}$ infection relies in IV acyclovir in case of disseminated and non-mucocutaneous disease, and in oral agents in case of non-severe disease.

\section{$V Z V$}

VZV is an alpha-herpesvirus acquired by an airborne route by exposure from patients with primary infection (chickenpox) or reactivation (herpes zoster-HZ). Given that most adults are seropositive to VZV, the main clinical presentation in lung transplant recipients is $\mathrm{HZ}$. HZ may affect up to $20 \%$ of lung transplant recipients within 5 years after transplant, i.e., 30 times more frequent than in the general population (167-170). Clinical presentation of chickenpox and $\mathrm{HZ}$ in lung transplant recipients are similar than in the general population, although with a higher risk for developing disseminated HZ. Extra-cutaneous manifestations are uncommon ( $5 \%$ in a recent series), mostly consisting in keratitis and CNS infection (164). Antiviral therapy with acyclovir is recommended for cases of chickenpox and $\mathrm{HZ}$ in lung transplant recipients. Although the IV form is preferred, oral therapy with valaciclovir of famciclovir can be safely given in non-severe cases. VZV seronegative transplant candidates should receive the life-attenuated varicella vaccine at least 4 weeks before transplantation. Varicella vaccine is generally contraindicated in the post-transplant period because of a potential risk of disseminated disease, although it has been safely given in selected pediatric liver transplant recipients (171). An inactivated adjuvanted zoster vaccine has shown to be highly effective to prevent shingles in immunocompetent adults and demonstrated promising safety profile in kidney transplant recipients, although there are limited data in lung transplantation (172).

\section{Human-berpes virus-6 (HHV-6) and -7}

HHV-6 and HHV-7 belong to the subfamily betaherpesvirinae with a seroprevalence in adults that exceeds $90 \%$ (173), as primary infection is usually acquired during the first years of life. The potential pathogenic role of HHV-7 has not been established yet (174). HHV-6 has the characteristic to persist by integration of HHV6 DNA sequences in the human genome, specifically in the telomeric area of all 


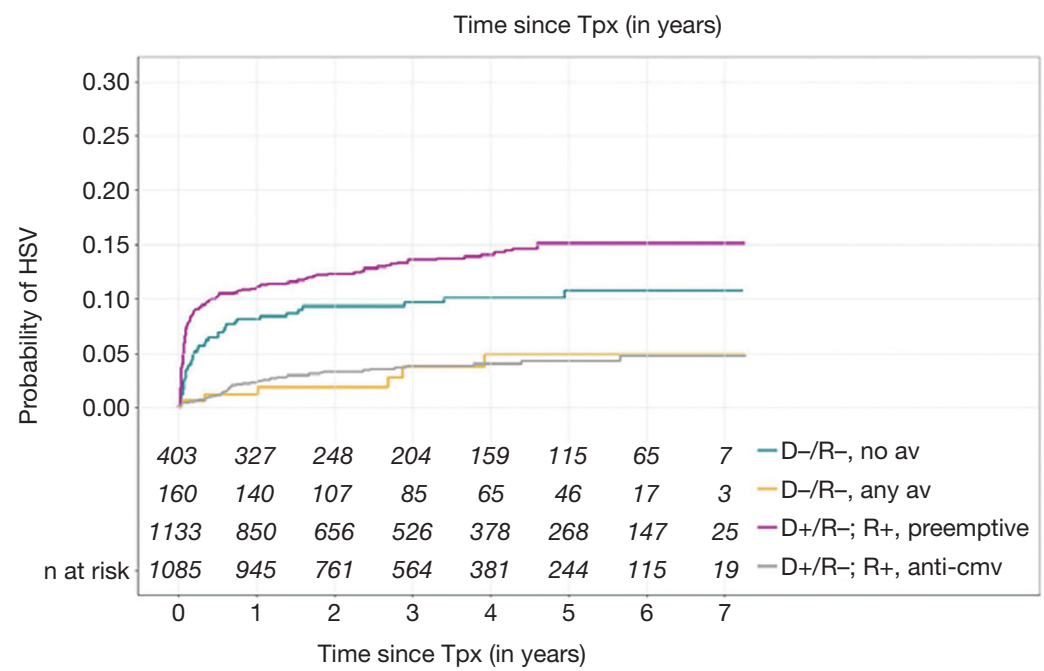

Figure 2 Probability of HSV infection after transplantation according to CMV serostatus and antiviral preventive strategy (164). Probability of HSV infection in CMV D-/R- patients receiving antiviral (av) prophylaxis (yellow line), CMV D+/R- or R+ patients receiving antiviral prophylaxis (grey line), CMV D-/R- patients not receiving antiviral prophylaxis (green line), and CMV D+/R- or R+ followed by the preemptive CMV approach (magenta line) $(\mathrm{P}<0.001$, all four groups). HSV, Herpes-Simplex virus; CMV, cytomegalovirus.

chromosomes, an entity named chromosomal-integratedHHV-6 (ciHHV6) $(175,176)$. It is not completely understood whether HHV-6 can reactivate in patients with ciHHV-6. Because patients with ciHHV-6 have high viral loads of HHV-6 genome in their blood samples without clinical significance, the interpretation of PCR for the diagnosis of active HHV-6 infection may be challenging. The most frequent clinical manifestations of HHV-6 disease in lung transplant recipients are fever, skin rash, and bone marrow suppression (177-179). HHV-6 CNS infection presents as limbic encephalitis, although it is rare in lung transplant recipients. Pre-transplant HHV-6 serostatus screening of donor and recipients is not recommended based on the current evidence of low rate of disease. Of note, asymptomatic replication of HHV-6 in the lung allograft is common, with uncertain clinical significance (180). Ganciclovir and foscarnet are the drugs of choice for therapy of HHV-6.

\section{Human-herpes virus-8 (HHV-8)}

$\mathrm{HHV}-8$ belongs to the gamma-herpesvirinae family. HHV8 is a non-ubiquitous virus, with a diverse seroprevalence depending on the geographic regions, being $50 \%$ in Africa, $10-30 \%$ in Europe, and $<10 \%$ in North America (181). The incidence of Kaposi sarcoma is 50 to 200 -fold higher in SOT recipients than in the general population (182).
HHV-8 serology is not routinely performed for the screening of organ and recipients, because low specificity, although it may be considered in endemic geographic regions. Of note, clusters of donor-derived HHV-8 infection have been described (183). The most common clinical manifestation of HHV-8-associated disease is Kaposi sarcoma. Mucocutaneous disease occurs in $90 \%$ of the cases, but visceral involvement can also be present in $60 \%$ of the cases. Other severe manifestations of HHV-8 disease include multicentric Castleman disease and primary effusion lymphoma $(184,185)$. The main therapeutic strategy is reduction of immunosuppression (186). A switch from calcineurin inhibitors to mTOR inhibitors has been associated with resolution of Kaposi sarcoma lesions, but relapse may occur (186-188). Intralesional chemotherapy, surgical excision, and radiation therapy can be used if lesion do not regress with immunosuppression reduction. Visceral or severe disease often require systemic chemotherapy (186).

\section{Human immunodeficiency virus (HIV)}

In the past, HIV infection was considered an absolute contraindication to lung transplantation. With the advent of antiretroviral therapy, prognosis of HIV-infected persons has improved dramatically with extended life expectancy (189). Consequently, organ transplantation has become increasingly common in people living with HIV. 
Lung transplantation remains rare in this population but is increasing in numbers $(190,191)$, as HIV infection is an independent risk factor for chronic obstructive pulmonary disease, interstitial lung disease, and pulmonary arterial hypertension (192-195). Data from large multicentre prospective studies for HIV-infected thoracic transplant recipients are lacking, and recommendations for management are extrapolated from the kidney transplant experience (196). Transplantation of organs from HIVpositive donors are now considered for HIV-positive recipients, given the need to expand the donor pool. Experience in South Africa and the US has shown good outcomes in kidney and in liver transplantation, with no increased acute rejection or mortality (197).

\section{Other viral infections}

\section{Norovirus}

Norovirus is the most common viral cause of epidemic gastroenteritis worldwide (198-200), with an incidence peak during the winter months (201). In SOT recipients, norovirus has been documented in up to $8 \%$ episodes of community-acquired diarrhea (202). Norovirus commonly causes an acute disease with nausea, vomiting, and diarrhea that typically self-resolved with $2-3$ days (203), but in immunocompromised patients it can result in chronic diarrhea that can last for months $(204,205)$. In a retrospective study, $23 \%$ of SOT recipients with norovirus infection developed a chronic presentation, associated with intestinal histopathologic changes such as disorganization and flattening of the intestinal epithelium $(205,206)$. Stool viral shedding for several months has also been described $(204,206)$. There is no specific treatment for norovirus infection, although an ongoing trial is evaluating the efficacy of nitazoxanide in SOT recipients.

\section{Parvovirus B19}

Human parvovirus B19 infection occurs worldwide and seroprevalence in adults is estimated to be $50-80 \%$ (202,207). A study reporting 98 cases of parvovirus B19 in SOT recipients (including 12 thoracic organ transplant recipients) observed a median time onset of 1.75 months after transplantation. The main clinical manifestation of parvovirus B19 infection in lung transplant recipients is chronic anaemia, with leukopenia and thrombocytopenia can be observed in around one third of patients. Hepatitis, pneumonitis, myocarditis and allograft dysfunction are also described (208). Diagnosis in SOT recipients is based on detection of DNAemia by PCR. Use of IVIG and reduction of immunosuppression are usually associated with good outcomes (although relapses are common) (209).

\section{Conclusions}

Over the last years, we have seen significant advances on the management of viral infections after lung transplantation. The implementation of universal preventive strategies and oral treatment against CMV has greatly reduced the impact of CMV and other herpesviruses after transplant. This is true not only for the direct effect of CMV replication, but also for $\mathrm{CMV}$-associated immunomodulatory effects $(111,164)$. Consequently, fatal cases of herpesvirus infections in lung transplant recipients are rarely seen nowadays. Universal influenza vaccination and early administration of NAI have reduced the burden of influenza-associated disease as well. However, there are still important unmet clinical needs for the management of viral infections in lung transplant recipients. First, the use of safer and more efficacious drugs for preventing and treating other respiratory viral infections, in particular for RSV and PIV, would potentially improve lung allograft outcomes. Although new drugs for difficult-to-treat CMV infection will be soon available, experience in lung transplant recipients is currently lacking. Second, the advent of new vaccines would potentially reduce the burden of disease of several viral infections with significant impact on lung transplantation (e.g., RSV or CMV). In addition, obtaining further evidence of the efficacy and safety of improved vaccines (e.g., high-dose influenza vaccine or adjuvanted zoster vaccine) would be essential for implementing these vaccines in the routine clinical practice. Third, the use of accurate biomarkers to determine the global or pathogenspecific state of immunosuppression would allow to personalize the implementation of specific preventive or therapeutic strategies in a given patient. While the use of cell-mediated immune assays for CMV is very promising, interventional trials are still ongoing. Finally, more data are needed for better understanding the impact of COVID-19 in lung transplant recipients, and how to better manage these patients in terms of immunomodulation of immunosuppression and use of new drugs. These efforts for assuring an appropriate management of viral complications after lung transplantation remain an essential step to continue improving survival and quality of life of lung 
transplant recipients.

\section{Acknowledgments}

Funding: None.

\section{Footnote}

Provenance and Peer Review: This article was commissioned by the Guest Editor (Jonathan D'Cunha) for the series "Lung Transplantation: Past, Present, and Future" published in fournal of Thoracic Disease. The article has undergone external peer review.

Conflicts of Interest: Both authors have completed the ICMJE uniform disclosure form (available at: https://dx.doi. org/10.21037/jtd-2021-24). The series "Lung Transplantation: Past, Present, and Future" was commissioned by the editorial office without any funding or sponsorship. OM reports grants from Lophius Bisociences, grants from Takeda, personal fees from MSD, during the conduct of the study; personal fees from Gilead, outside the submitted work. Both authors have no other conflicts of interest to declare.

Ethical Statement: Both authors are accountable for all aspects of the work in ensuring that questions related to the accuracy or integrity of any part of the work are appropriately investigated and resolved.

Open Access Statement: This is an Open Access article distributed in accordance with the Creative Commons Attribution-NonCommercial-NoDerivs 4.0 International License (CC BY-NC-ND 4.0), which permits the noncommercial replication and distribution of the article with the strict proviso that no changes or edits are made and the original work is properly cited (including links to both the formal publication through the relevant DOI and the license). See: https://creativecommons.org/licenses/by-nc-nd/4.0/.

\section{References}

1. Bailey ES, Zemke JN, Choi JY, et al. A Mini-Review of Adverse Lung Transplant Outcomes Associated With Respiratory Viruses. Front Immunol 2019;10:2861.

2. van Delden C, Stampf S, Hirsch HH, et al. Burden and Timeline of Infectious Diseases in the First Year After Solid Organ Transplantation in the Swiss Transplant Cohort Study. Clin Infect Dis 2020;71:e159-69.
3. Kumar D, Husain S, Chen $\mathrm{MH}$, et al. A prospective molecular surveillance study evaluating the clinical impact of community-acquired respiratory viruses in lung transplant recipients. Transplantation 2010;89:1028-33.

4. Gottlieb J, Schulz TF, Welte T, et al. Community-acquired respiratory viral infections in lung transplant recipients: a single season cohort study. Transplantation 2009;87:1530-7.

5. Gottlieb J. Community-acquired respiratory viruses. Curr Opin Organ Transplant 2019;24:311-7.

6. Zhu N, Zhang D, Wang W, et al. A Novel Coronavirus from Patients with Pneumonia in China, 2019. N Engl J Med 2020;382:727-33.

7. Pereira MR, Mohan S, Cohen DJ, et al. COVID-19 in solid organ transplant recipients: Initial report from the US epicenter. Am J Transplant 2020;20:1800-8.

8. Fernández-Ruiz M, Andrés A, Loinaz C, et al. COVID-19 in solid organ transplant recipients: A single-center case series from Spain. Am J Transplant 2020;20:1849-58.

9. Kates OS, Haydel BM, Florman SS, et al. COVID-19 in solid organ transplant: A multi-center cohort study. Clin Infect Dis 2020. [Epub ahead of print]. doi: 10.1093/cid/ ciaa1097.

10. Peghin M, Hirsch HH, Len Ó, et al. Epidemiology and Immediate Indirect Effects of Respiratory Viruses in Lung Transplant Recipients: A 5-Year Prospective Study. Am J Transplant 2017;17:1304-12.

11. Couch RB, Englund JA, Whimbey E. Respiratory viral infections in immunocompetent and immunocompromised persons. Am J Med 1997;102:2-9; discussion 25-6.

12. López-Medrano F, Aguado JM, Lizasoain M, et al. Clinical implications of respiratory virus infections in solid organ transplant recipients: a prospective study. Transplantation 2007;84:851-6.

13. Bridevaux PO, Aubert JD, Soccal PM, et al. Incidence and outcomes of respiratory viral infections in lung transplant recipients: a prospective study. Thorax 2014;69:32-8.

14. Billings JL, Hertz MI, Savik K, et al. Respiratory viruses and chronic rejection in lung transplant recipients. J Heart Lung Transplant 2002;21:559-66.

15. Vilchez R, McCurry K, Dauber J, et al. Influenza and parainfluenza respiratory viral infection requiring admission in adult lung transplant recipients. Transplantation 2002;73:1075-8.

16. van de Veerdonk FL, Kolwijck E, Lestrade PP, et al. Influenza-Associated Aspergillosis in Critically Ill Patients. Am J Respir Crit Care Med 2017;196:524-7.

17. Yusen RD, Edwards LB, Kucheryavaya AY, et al. The Registry of the International Society for Heart and Lung 
Transplantation: Thirty-second Official Adult Lung and Heart-Lung Transplantation Report--2015; Focus Theme: Early Graft Failure. J Heart Lung Transplant 2015;34:1264-77.

18. Benden C, Haughton M, Leonard S, et al. Therapy options for chronic lung allograft dysfunctionbronchiolitis obliterans syndrome following first-line immunosuppressive strategies: A systematic review. J Heart Lung Transplant 2017;36:921-33.

19. Chambers DC, Yusen RD, Cherikh WS, et al. The Registry of the International Society for Heart and Lung Transplantation: Thirty-fourth Adult Lung And HeartLung Transplantation Report-2017; Focus Theme: Allograft ischemic time. J Heart Lung Transplant 2017;36:1047-59.

20. Peghin M, Los-Arcos I, Hirsch HH, et al. Communityacquired Respiratory Viruses Are a Risk Factor for Chronic Lung Allograft Dysfunction. Clin Infect Dis 2019;69:1192-7.

21. Allyn PR, Duffy EL, Humphries RM, et al. Graft Loss and CLAD-Onset Is Hastened by Viral Pneumonia After Lung Transplantation. Transplantation 2016;100:2424-31.

22. Fisher CE, Preiksaitis CM, Lease ED, et al. Symptomatic Respiratory Virus Infection and Chronic Lung Allograft Dysfunction. Clin Infect Dis 2016;62:313-9.

23. Bridges ND, Spray TL, Collins MH, et al. Adenovirus infection in the lung results in graft failure after lung transplantation. J Thorac Cardiovasc Surg 1998;116:617-23.

24. Ison MG, Hirsch HH. Community-Acquired Respiratory Viruses in Transplant Patients: Diversity, Impact, Unmet Clinical Needs. Clin Microbiol Rev 2019;32:e0042-19.

25. Weinberg A, Lyu DM, Li S, et al. Incidence and morbidity of human metapneumovirus and other communityacquired respiratory viruses in lung transplant recipients. Transpl Infect Dis 2010;12:330-5.

26. Li L, Avery R, Budev M, et al. Oral versus inhaled ribavirin therapy for respiratory syncytial virus infection after lung transplantation. J Heart Lung Transplant 2012;31:839-44.

27. Ison MG. Respiratory viral infections in transplant recipients. Antivir Ther 2007;12:627-38.

28. Hopkins PM, Plit ML, Carter IW, et al. Indirect fluorescent antibody testing of nasopharyngeal swabs for influenza diagnosis in lung transplant recipients. J Heart Lung Transplant 2003;22:161-8.

29. Khalifah AP, Hachem RR, Chakinala MM, et al. Respiratory viral infections are a distinct risk for bronchiolitis obliterans syndrome and death. Am J Respir
Crit Care Med 2004;170:181-7.

30. Magnusson J, Westin J, Andersson LM, et al. The impact of viral respiratory tract infections on long-term morbidity and mortality following lung transplantation: a retrospective cohort study using a multiplex PCR panel. Transplantation 2013;95:383-8.

31. Collins JP, Campbell AP, Openo K, et al. Outcomes of Immunocompromised Adults Hospitalized With Laboratory-confirmed Influenza in the United States, 2011-2015. Clin Infect Dis 2020;70:2121-30.

32. Vilchez RA, McCurry K, Dauber J, et al. Influenza virus infection in adult solid organ transplant recipients. Am J Transplant 2002;2:287-91.

33. Meylan PR, Aubert JD, Kaiser L. Influenza transmission to recipient through lung transplantation. Transpl Infect Dis 2007;9:55-7.

34. Kumar D, Ferreira VH, Blumberg E, et al. A 5-Year Prospective Multicenter Evaluation of Influenza Infection in Transplant Recipients. Clin Infect Dis 2018;67:1322-9.

35. Kumar D, Michaels MG, Morris MI, et al. Outcomes from pandemic influenza A H1N1 infection in recipients of solid-organ transplants: a multicentre cohort study. Lancet Infect Dis 2010;10:521-6.

36. Ison MG, Sharma A, Shepard JA, et al. Outcome of influenza infection managed with oseltamivir in lung transplant recipients. J Heart Lung Transplant 2008;27:282-8.

37. Manuel O, Estabrook M; American Society of Transplantation Infectious Diseases Community of Practice. RNA respiratory viral infections in solid organ transplant recipients: Guidelines from the American Society of Transplantation Infectious Diseases Community of Practice. Clin Transplant 2019;33:e13511.

38. Ison MG. Antivirals and resistance: influenza virus. Curr Opin Virol 2011;1:563-73.

39. Lackenby A, Besselaar TG, Daniels RS, et al. Global update on the susceptibility of human influenza viruses to neuraminidase inhibitors and status of novel antivirals, 2016-2017. Antiviral Res 2018;157:38-46.

40. Ikematsu H, Hayden FG, Kawaguchi K, et al. Baloxavir Marboxil for Prophylaxis against Influenza in Household Contacts. N Engl J Med 2020;383:309-20.

41. Hayden FG, Sugaya N, Hirotsu N, et al. Baloxavir Marboxil for Uncomplicated Influenza in Adults and Adolescents. N Engl J Med 2018;379:913-23.

42. Helanterä I, Anttila VJ, Lappalainen M, et al. Outbreak of Influenza A(H1N1) in a Kidney Transplant UnitProtective Effect of Vaccination. Am J Transplant 
2015;15:2470-4.

43. Hurst FP, Lee JJ, Jindal RM, et al. Outcomes associated with influenza vaccination in the first year after kidney transplantation. Clin J Am Soc Nephrol 2011;6:1192-7.

44. Schuurmans MM, Tini GM, Dalar L, et al. Pandemic 2009 H1N1 influenza virus vaccination in lung transplant recipients: coverage, safety and clinical effectiveness in the Zurich cohort. J Heart Lung Transplant 2011;30:685-90.

45. Natori Y, Shiotsuka M, Slomovic J, et al. A DoubleBlind, Randomized Trial of High-Dose vs StandardDose Influenza Vaccine in Adult Solid-Organ Transplant Recipients. Clin Infect Dis 2018;66:1698-704.

46. Cordero E, Roca-Oporto C, Bulnes-Ramos A, et al. Two Doses of Inactivated Influenza Vaccine Improve Immune Response in Solid Organ Transplant Recipients: Results of TRANSGRIPE 1-2, a Randomized Controlled Clinical Trial. Clin Infect Dis 2017;64:829-38.

47. Kumar D, Campbell P, Hoschler K, et al. Randomized Controlled Trial of Adjuvanted Versus Nonadjuvanted Influenza Vaccine in Kidney Transplant Recipients. Transplantation 2016;100:662-9.

48. Danziger-Isakov L, Kumar D; AST ID Community of Practice. Vaccination of solid organ transplant candidates and recipients: Guidelines from the American society of transplantation infectious diseases community of practice. Clin Transplant 2019;33:e13563.

49. Permpalung N, Thaniyavarn T, Saullo JL, et al. Oral and Inhaled Ribavirin Treatment for Respiratory Syncytial Virus Infection in Lung Transplant Recipients. Transplantation 2020;104:1280-6.

50. Trang TP, Whalen M, Hilts-Horeczko A, et al. Comparative effectiveness of aerosolized versus oral ribavirin for the treatment of respiratory syncytial virus infections: A single-center retrospective cohort study and review of the literature. Transpl Infect Dis 2018;20:e12844.

51. Hopkins P, McNeil K, Kermeen F, et al. Human metapneumovirus in lung transplant recipients and comparison to respiratory syncytial virus. Am J Respir Crit Care Med 2008;178:876-81.

52. Pelaez A, Lyon GM, Force SD, et al. Efficacy of oral ribavirin in lung transplant patients with respiratory syncytial virus lower respiratory tract infection. J Heart Lung Transplant 2009;28:67-71.

53. Mombelli M, Lang BM, Neofytos D, et al. Burden, epidemiology, and outcomes of microbiologically confirmed respiratory viral infections in solid organ transplant recipients: a nationwide, multi-season prospective cohort study. Am J Transplant 2021;21:1789-800.
54. Burrows FS, Carlos LM, Benzimra M, et al. Oral ribavirin for respiratory syncytial virus infection after lung transplantation: Efficacy and cost-efficiency. J Heart Lung Transplant 2015;34:958-62.

55. Paulsen GC, Danziger-Isakov L. Respiratory Viral Infections in Solid Organ and Hematopoietic Stem Cell Transplantation. Clin Chest Med 2017;38:707-26.

56. Chemaly RF, Dadwal SS, Bergeron A, et al. A Phase 2, Randomized, Double-blind, Placebo-Controlled Trial of Presatovir for the Treatment of Respiratory Syncytial Virus Upper Respiratory Tract Infection in Hematopoietic-Cell Transplant Recipients. Clin Infect Dis 2020;71:2777-86.

57. Marty FM, Chemaly RF, Mullane KM, et al. A Phase 2b, Randomized, Double-blind, Placebo-Controlled Multicenter Study Evaluating Antiviral Effects, Pharmacokinetics, Safety, and Tolerability of Presatovir in Hematopoietic Cell Transplant Recipients with Respiratory Syncytial Virus Infection of the Lower Respiratory Tract. Clin Infect Dis 2020;71:2787-95.

58. Jalal H, Bibby DF, Bennett J, et al. Molecular investigations of an outbreak of parainfluenza virus type 3 and respiratory syncytial virus infections in a hematology unit. J Clin Microbiol 2007;45:1690-6.

59. Chalkias S, Mackenzie MR, Gay C, et al. DAS181 treatment of hematopoietic stem cell transplant patients with parainfluenza virus lung disease requiring mechanical ventilation. Transpl Infect Dis 2014;16:141-4.

60. Guzmán-Suarez BB, Buckley MW, Gilmore ET, et al. Clinical potential of DAS181 for treatment of parainfluenza-3 infections in transplant recipients. Transpl Infect Dis 2012;14:427-33.

61. Drozd DR, Limaye AP, Moss RB, et al. DAS181 treatment of severe parainfluenza type 3 pneumonia in a lung transplant recipient. Transpl Infect Dis 2013;15:E28-32.

62. Ison MG, Hayden RT. Adenovirus. Microbiol Spectr 2016. doi: 10.1128/microbiolspec.DMIH2-0020-2015.

63. Kaiser L, Aubert JD, Pache JC, et al. Chronic rhinoviral infection in lung transplant recipients. Am J Respir Crit Care Med 2006;174:1392-9.

64. Kumar D, Tellier R, Draker R, et al. Severe Acute Respiratory Syndrome (SARS) in a liver transplant recipient and guidelines for donor SARS screening. Am J Transplant 2003;3:977-81.

65. Wu Z, McGoogan JM. Characteristics of and Important Lessons From the Coronavirus Disease 2019 (COVID-19) Outbreak in China: Summary of a Report of 72314 Cases From the Chinese Center for Disease Control and Prevention. JAMA 2020;323:1239-42. 
66. Gupta A, Madhavan MV, Sehgal K, et al. Extrapulmonary manifestations of COVID-19. Nat Med 2020;26:1017-32.

67. Kumar D, Manuel O, Natori Y, et al. COVID-19: A global transplant perspective on successfully navigating a pandemic. Am J Transplant 2020;20:1773-9.

68. Caillard S, Chavarot N, Francois H, et al. Is COVID-19 infection more severe in kidney transplant recipients? Am J Transplant 2021;21:1295-303.

69. Messika J, Eloy P, Roux A, et al. COVID-19 in Lung Transplant Recipients. Transplantation 2021;105:177-86.

70. The RECOVERY Collaborative Group. Dexamethasone in Hospitalized Patients with COVID-19. N Engl J Med 2021;384:693-704.

71. Angus DC, Berry S, Lewis RJ, et al. The REMAP-CAP (Randomized Embedded Multifactorial Adaptive Platform for Community-acquired Pneumonia) Study. Rationale and Design. Ann Am Thorac Soc 2020;17:879-91.

72. Beigel JH, Tomashek KM, Dodd LE. Remdesivir for the Treatment of COVID-19 - final report. N Engl J Med 2020;383:1813-26.

73. WHO Solidarity Trial Consortium; Pan H, Peto R, et al. Repurposed Antiviral Drugs for COVID-19 Interim WHO Solidarity Trial Results. N Engl J Med 2021;384:497-511.

74. Rochwerg B, Siemieniuk RA, Agoritsas T, et al. A living WHO guideline on drugs for COVID-19. BMJ 2020;370:m3379.

75. Hueso T, Pouderoux C, Péré H, et al. Convalescent plasma therapy for B-cell-depleted patients with protracted COVID-19. Blood 2020;136:2290-5.

76. Libster R, Pérez Marc G, Wappner D, et al. Early HighTiter Plasma Therapy to Prevent Severe COVID-19 in Older Adults. N Engl J Med 2021;384:610-8.

77. Weinreich DM, Sivapalasingam S, Norton T, et al. REGNCOV2, a Neutralizing Antibody Cocktail, in Outpatients with COVID-19. N Engl J Med 2021;384:238-51.

78. Tschopp J, L'Huillier AG, Mombelli M, et al. First experience of SARS-CoV-2 infections in solid organ transplant recipients in the Swiss Transplant Cohort Study. Am J Transplant 2020;20:2876-82.

79. Verleden GM, Godinas L, Lorent N, et al. COVID-19 in lung transplant patients: A case series. Am J Transplant 2020;20:3234-8.

80. Moosavi SA, Mashhadiagha A, Motazedian N, et al. COVID-19 clinical manifestations and treatment strategies among solid-organ recipients: A systematic review of cases. Transpl Infect Dis 2020;22:e13427.

81. International Society for Heart and Lung Transplantation.
Guidance for Cardiothoracic Transplant and Ventricular Assist Device Centers regarding the SARS-CoV-2 pandemic2020.

82. Shah MB, Lynch RJ, El-Haddad H, et al. Utilization of deceased donors during a pandemic: argument against using SARS-CoV-2-positive donors. Am J Transplant 2020;20:1795-9.

83. American Society of Transplantation Infectious Diseases Community. COVID-19 (Coronavirus): FAQs for Organ Transplantation 2020.

84. Kaul DR, Valesano AL, Petrie JG, et al. Donor to recipient transmission of SARS-CoV-2 by lung transplantation despite negative donor upper respiratory tract testing. Am J Transplant 2021. [Epub ahead of print]. doi: 10.1111/ ajt.16532.

85. Grupper A, Rabinowich L, Schwartz D, et al. Reduced humoral response to mRNA SARS-CoV-2 BNT162b2 vaccine in kidney transplant recipients without prior exposure to the virus. Am J Transplant 2021. [Epub ahead of print]. doi: 10.1111/ajt.16615.

86. Boyarsky BJ, Werbel WA, Avery RK, et al. Immunogenicity of a Single Dose of SARS-CoV-2 Messenger RNA Vaccine in Solid Organ Transplant Recipients. JAMA 2021;325:1784-6.

87. Ison MG. Adenovirus infections in transplant recipients. Clin Infect Dis 2006;43:331-9.

88. Florescu DF, Schaenman JM; AST Infectious Diseases Community of Practice. Adenovirus in solid organ transplant recipients: Guidelines from the American Society of Transplantation Infectious Diseases Community of Practice. Clin Transplant 2019;33:e13527.

89. Florescu DF, Pergam SA, Neely MN, et al. Safety and efficacy of CMX001 as salvage therapy for severe adenovirus infections in immunocompromised patients. Biol Blood Marrow Transplant 2012;18:731-8.

90. Matthes-Martin S, Feuchtinger T, Shaw PJ, et al. European guidelines for diagnosis and treatment of adenovirus infection in leukemia and stem cell transplantation: summary of ECIL-4 (2011). Transpl Infect Dis 2012;14:555-63.

91. Bate SL, Dollard SC, Cannon MJ. Cytomegalovirus seroprevalence in the United States: the national health and nutrition examination surveys, 1988-2004. Clin Infect Dis 2010;50:1439-47.

92. Cannon MJ, Schmid DS, Hyde TB. Review of cytomegalovirus seroprevalence and demographic characteristics associated with infection. Rev Med Virol 2010;20:202-13. 
93. Razonable RR, Humar A. Cytomegalovirus in solid organ transplant recipients-Guidelines of the American Society of Transplantation Infectious Diseases Community of Practice. Clin Transplant 2019;33:e13512.

94. Helanterä I, Schachtner T, Hinrichs C, et al. Current characteristics and outcome of cytomegalovirus infections after kidney transplantation. Transpl Infect Dis 2014;16:568-77.

95. Ljungman P, Boeckh M, Hirsch HH, et al. Definitions of Cytomegalovirus Infection and Disease in Transplant Patients for Use in Clinical Trials. Clin Infect Dis 2017;64:87-91.

96. Manuel O, Husain S, Kumar D, et al. Assessment of cytomegalovirus-specific cell-mediated immunity for the prediction of cytomegalovirus disease in high-risk solidorgan transplant recipients: a multicenter cohort study. Clin Infect Dis 2013;56:817-24.

97. Manuel O, Pang XL, Humar A, et al. An assessment of donor-to-recipient transmission patterns of human cytomegalovirus by analysis of viral genomic variants. J Infect Dis 2009;199:1621-8.

98. Meesing A, Abraham RS, Razonable RR. Clinical Correlation of Cytomegalovirus Infection With CMVspecific CD8+ T-cell Immune Competence Score and Lymphocyte Subsets in Solid Organ Transplant Recipients. Transplantation 2019;103:832-8.

99. Meylan PR, Manuel O. Late-onset cytomegalovirus disease in patients with solid organ transplant. Curr Opin Infect Dis 2007;20:412-8.

100.Pascual J, Royuela A, Fernández AM, et al. Role of mTOR inhibitors for the control of viral infection in solid organ transplant recipients. Transpl Infect Dis 2016;18:819-31.

101. Rubin RH. The indirect effects of cytomegalovirus infection on the outcome of organ transplantation. JAMA 1989;261:3607-9.

102. Madalosso C, de Souza NF Jr, Ilstrup DM, et al. Cytomegalovirus and its association with hepatic artery thrombosis after liver transplantation. Transplantation 1998;66:294-7.

103. Jeejeebhoy FM, Zaltzman JS. Thrombotic microangiopathy in association with cytomegalovirus infection in a renal transplant patient: a new treatment strategy. Transplantation 1998;65:1645-8.

104. Snyder LD, Finlen-Copeland CA, Turbyfill WJ, et al. Cytomegalovirus pneumonitis is a risk for bronchiolitis obliterans syndrome in lung transplantation. Am J Respir Crit Care Med 2010;181:1391-6.

105.Paraskeva M, Bailey M, Levvey BJ, et al. Cytomegalovirus replication within the lung allograft is associated with bronchiolitis obliterans syndrome. Am J Transplant 2011;11:2190-6.

106. Hakimi Z, Aballéa S, Ferchichi S, et al. Burden of cytomegalovirus disease in solid organ transplant recipients: a national matched cohort study in an inpatient setting. Transpl Infect Dis 2017. doi: 10.1111/tid.12732.

107.Stern M, Hirsch H, Cusini A, et al. Cytomegalovirus serology and replication remain associated with solid organ graft rejection and graft loss in the era of prophylactic treatment. Transplantation 2014;98:1013-8.

108. Wagner JA, Ross H, Hunt S, et al. Prophylactic ganciclovir treatment reduces fungal as well as cytomegalovirus infections after heart transplantation. Transplantation 1995;60:1473-7.

109. Reinke P, Prösch S, Kern F, et al. Mechanisms of human cytomegalovirus (HCMV) (re)activation and its impact on organ transplant patients. Transpl Infect Dis 1999;1:157-64.

110.Chmiel C, Speich R, Hofer M, et al. Ganciclovir/ valganciclovir prophylaxis decreases cytomegalovirusrelated events and bronchiolitis obliterans syndrome after lung transplantation. Clin Infect Dis 2008;46:831-9.

111.Jaamei N, Koutsokera A, Pasquier J, et al. Clinical significance of post-prophylaxis cytomegalovirus infection in lung transplant recipients. Transpl Infect Dis 2018;20:e12893.

112. Manuel O, Kralidis G, Mueller NJ, et al. Impact of antiviral preventive strategies on the incidence and outcomes of cytomegalovirus disease in solid organ transplant recipients. Am J Transplant 2013;13:2402-10.

113.Palmer SM, Limaye AP, Banks M, et al. Extended valganciclovir prophylaxis to prevent cytomegalovirus after lung transplantation: a randomized, controlled trial. Ann Intern Med 2010;152:761-9.

114. Paya C, Humar A, Dominguez E, et al. Efficacy and safety of valganciclovir vs. oral ganciclovir for prevention of cytomegalovirus disease in solid organ transplant recipients. Am J Transplant 2004;4:611-20.

115.Munoz-Price LS, Slifkin M, Ruthazer R, et al. The clinical impact of ganciclovir prophylaxis on the occurrence of bacteremia in orthotopic liver transplant recipients. Clin Infect Dis 2004;39:1293-9.

116. Kliem V, Fricke L, Wollbrink T, et al. Improvement in long-term renal graft survival due to $\mathrm{CMV}$ prophylaxis with oral ganciclovir: results of a randomized clinical trial. Am J Transplant 2008;8:975-83.

117. Couzi L, Helou S, Bachelet T, et al. High incidence of anticytomegalovirus drug resistance among D+R- kidney 
transplant recipients receiving preemptive therapy. Am J Transplant 2012;12:202-9.

118. Frange P, Leruez-Ville M. Maribavir, brincidofovir and letermovir: Efficacy and safety of new antiviral drugs for treating cytomegalovirus infections. Med Mal Infect 2018;48:495-502.

119. Chou S. Rapid In Vitro Evolution of Human Cytomegalovirus UL56 Mutations That Confer Letermovir Resistance. Antimicrob Agents Chemother 2015;59:6588-93.

120. Cherrier L, Nasar A, Goodlet KJ, et al. Emergence of letermovir resistance in a lung transplant recipient with ganciclovir-resistant cytomegalovirus infection. Am J Transplant 2018;18:3060-4.

121. Aryal S, Katugaha SB, Cochrane A, et al. Single-center experience with use of letermovir for CMV prophylaxis or treatment in thoracic organ transplant recipients. Transpl Infect Dis 2019;21:e13166.

122. Veit T, Munker D, Kauke T, et al. Letermovir for Difficult to Treat Cytomegalovirus Infection in Lung Transplant Recipients. Transplantation 2020;104:410-4.

123. Yong MK, Lewin SR, Manuel O. Immune Monitoring for CMV in Transplantation. Curr Infect Dis Rep 2018;20:4.

124. Westall GP, Cristiano Y, Levvey BJ, et al. A Randomized Study of Quantiferon CMV-directed Versus Fixedduration Valganciclovir Prophylaxis to Reduce Late CMV After Lung Transplantation. Transplantation 2019;103:1005-13.

125.Asberg A, Humar A, Rollag H, et al. Oral valganciclovir is noninferior to intravenous ganciclovir for the treatment of cytomegalovirus disease in solid organ transplant recipients. Am J Transplant 2007;7:2106-13.

126. Kumar D, Chin-Hong P, Kayler L, et al. A prospective multicenter observational study of cell-mediated immunity as a predictor for cytomegalovirus infection in kidney transplant recipients. Am J Transplant 2019;19:2505-16.

127.Limaye AP, Raghu G, Koelle DM, et al. High incidence of ganciclovir-resistant cytomegalovirus infection among lung transplant recipients receiving preemptive therapy. J Infect Dis 2002;185:20-7.

128. Limaye AP, Corey L, Koelle DM, et al. Emergence of ganciclovir-resistant cytomegalovirus disease among recipients of solid-organ transplants. Lancet 2000;356:645-9.

129. Eid AJ, Arthurs SK, Deziel PJ, et al. Emergence of drugresistant cytomegalovirus in the era of valganciclovir prophylaxis: therapeutic implications and outcomes. Clin Transplant 2008;22:162-70.
130. Chou S. Cytomegalovirus UL97 mutations in the era of ganciclovir and maribavir. Rev Med Virol 2008;18:233-46.

131. Chou SW. Cytomegalovirus drug resistance and clinical implications. Transpl Infect Dis 2001;3 Suppl 2:20-4.

132. Emery VC. Progress in understanding cytomegalovirus drug resistance. J Clin Virol 2001;21:223-8.

133. Papanicolaou GA, Silveira FP, Langston AA, et al. Maribavir for Refractory or Resistant Cytomegalovirus Infections in Hematopoietic-cell or Solid-organ Transplant Recipients: A Randomized, Dose-ranging, Double-blind, Phase 2 Study. Clin Infect Dis 2019;68:1255-64.

134. Green M, Michaels MG. Epstein-Barr virus infection and posttransplant lymphoproliferative disorder. Am J Transplant 2013;13 Suppl 3:41-54; quiz 54.

135.Leyssens A, Dierickx D, Verbeken EK, et al. Posttransplant lymphoproliferative disease in lung transplantation: A nested case-control study. Clin Transplant 2017. doi: 10.1111/ctr.12983.

136. Parker A, Bowles K, Bradley JA, et al. Management of post-transplant lymphoproliferative disorder in adult solid organ transplant recipients - BCSH and BTS Guidelines. Br J Haematol 2010;149:693-705.

137.Adami J, Gäbel H, Lindelöf B, et al. Cancer risk following organ transplantation: a nationwide cohort study in Sweden. Br J Cancer 2003;89:1221-7.

138. Walker RC, Marshall WF, Strickler JG, et al. Pretransplantation assessment of the risk of lymphoproliferative disorder. Clin Infect Dis 1995;20:1346-53.

139. Cockfield SM. Identifying the patient at risk for posttransplant lymphoproliferative disorder. Transpl Infect Dis 2001;3:70-8.

140.Na R, Grulich AE, Meagher NS, et al. Comparison of de novo cancer incidence in Australian liver, heart and lung transplant recipients. Am J Transplant 2013;13:174-83.

141. Engels EA, Pfeiffer RM, Fraumeni JF Jr, et al. Spectrum of cancer risk among US solid organ transplant recipients. JAMA 2011;306:1891-901.

142. Walker RC, Paya CV, Marshall WF, et al. Pretransplantation seronegative Epstein-Barr virus status is the primary risk factor for posttransplantation lymphoproliferative disorder in adult heart, lung, and other solid organ transplantations. J Heart Lung Transplant 1995;14:214-21.

143. Armitage JM, Kormos RL, Stuart RS, et al. Posttransplant lymphoproliferative disease in thoracic organ transplant patients: ten years of cyclosporinebased immunosuppression. J Heart Lung Transplant 
1991;10:877-86; discussion 886-7.

144. Aris RM, Maia DM, Neuringer IP, et al. Posttransplantation lymphoproliferative disorder in the Epstein-Barr virus-naïve lung transplant recipient. Am J Respir Crit Care Med 1996;154:1712-7.

145. Opelz G, Döhler B. Lymphomas after solid organ transplantation: a collaborative transplant study report. Am J Transplant 2004;4:222-30.

146. Dierickx D, Tousseyn T, Sagaert X, et al. Singlecenter analysis of biopsy-confirmed posttransplant lymphoproliferative disorder: incidence, clinicopathological characteristics and prognostic factors. Leuk Lymphoma 2013;54:2433-40.

147.Dierickx D, Habermann TM. Post-Transplantation Lymphoproliferative Disorders in Adults. N Engl J Med 2018;378:549-62.

148. Caillard S, Porcher R, Provot F, et al. Post-transplantation lymphoproliferative disorder after kidney transplantation: report of a nationwide French registry and the development of a new prognostic score. J Clin Oncol 2013;31:1302-9.

149. Kinch A, Baecklund E, Backlin C, et al. A population-based study of 135 lymphomas after solid organ transplantation: The role of Epstein-Barr virus, hepatitis $\mathrm{C}$ and diffuse large B-cell lymphoma subtype in clinical presentation and survival. Acta Oncol 2014;53:669-79.

150. Wagner HJ, Wessel M, Jabs W, et al. Patients at risk for development of posttransplant lymphoproliferative disorder: plasma versus peripheral blood mononuclear cells as material for quantification of Epstein-Barr viral load by using real-time quantitative polymerase chain reaction. Transplantation 2001;72:1012-9.

151. Stevens SJ, Verschuuren EA, Pronk I, et al. Frequent monitoring of Epstein-Barr virus DNA load in unfractionated whole blood is essential for early detection of posttransplant lymphoproliferative disease in high-risk patients. Blood 2001;97:1165-71.

152. Cho YU, Chi HS, Jang S, et al. Pattern analysis of Epstein-Barr virus viremia and its significance in the evaluation of organ transplant patients suspected of having posttransplant lymphoproliferative disorders. Am J Clin Pathol 2014;141:268-74.

153.San-Juan R, Comoli P, Caillard S, et al. Epstein-Barr virus-related post-transplant lymphoproliferative disorder in solid organ transplant recipients. Clin Microbiol Infect 2014;20 Suppl 7:109-18.

154.van Esser JW, van der Holt B, Meijer E, et al. Epstein-Barr virus $(\mathrm{EBV})$ reactivation is a frequent event after allogeneic stem cell transplantation (SCT) and quantitatively predicts EBV-lymphoproliferative disease following T-cell-depleted SCT. Blood 2001;98:972-8.

155. Tsai DE, Douglas L, Andreadis C, et al. EBV PCR in the diagnosis and monitoring of posttransplant lymphoproliferative disorder: results of a two-arm prospective trial. Am J Transplant 2008;8:1016-24.

156. Rasche L, Kapp M, Einsele H, et al. EBV-induced post transplant lymphoproliferative disorders: a persisting challenge in allogeneic hematopoetic SCT. Bone Marrow Transplant 2014;49:163-7.

157. Choquet S, Varnous S, Deback C, et al. Adapted treatment of Epstein-Barr virus infection to prevent posttransplant lymphoproliferative disorder after heart transplantation. Am J Transplant 2014;14:857-66.

158. Trappe R, Oertel S, Leblond V, et al. Sequential treatment with rituximab followed by CHOP chemotherapy in adult B-cell post-transplant lymphoproliferative disorder (PTLD): the prospective international multicentre phase 2 PTLD-1 trial. Lancet Oncol 2012;13:196-206.

159. Merlo A, Turrini R, Dolcetti R, et al. The interplay between Epstein-Barr virus and the immune system: a rationale for adoptive cell therapy of EBV-related disorders. Haematologica 2010;95:1769-77.

160. Dharnidharka VR, Mohanakumar T. New approaches to treating B-cell cancers induced by Epstein-Barr virus. $\mathrm{N}$ Engl J Med 2015;372:569-71.

161. Fishman JA. Overview: cytomegalovirus and the herpesviruses in transplantation. Am J Transplant 2013;13 Suppl 3:1-8; quiz 8.

162. Heininger U, Seward JF. Varicella. Lancet 2006;368:1365-76.

163. Shaw BI, Nanavati AJ, Taylor V, et al. Donor derived HSV hepatitis in a kidney transplant recipient leading to liver fibrosis and portal hypertension. Transpl Infect Dis 2019;21:e13029.

164.Martin-Gandul C, Stampf S, Héquet D, et al. Preventive Strategies Against Cytomegalovirus and Incidence of $\alpha$-Herpesvirus Infections in Solid Organ Transplant Recipients: A Nationwide Cohort Study. Am J Transplant 2017;17:1813-22.

165.Zuckerman RA, Limaye AP. Varicella zoster virus (VZV) and herpes simplex virus (HSV) in solid organ transplant patients. Am J Transplant 2013;13 Suppl 3:55-66; quiz 66.

166. Lowance D, Neumayer HH, Legendre CM, et al. Valacyclovir for the prevention of cytomegalovirus disease after renal transplantation. International Valacyclovir Cytomegalovirus Prophylaxis Transplantation Study 
Group. N Engl J Med 1999;340:1462-70.

167. Gourishankar S, McDermid JC, Jhangri GS, et al. Herpes zoster infection following solid organ transplantation: incidence, risk factors and outcomes in the current immunosuppressive era. Am J Transplant 2004;4:108-15.

168. Manuel O, Kumar D, Singer LG, et al. Incidence and clinical characteristics of herpes zoster after lung transplantation. J Heart Lung Transplant 2008;27:11-6.

169. Donahue JG, Choo PW, Manson JE, et al. The incidence of herpes zoster. Arch Intern Med 1995;155:1605-9.

170. Oxman MN, Levin MJ, Johnson GR, et al. A vaccine to prevent herpes zoster and postherpetic neuralgia in older adults. N Engl J Med 2005;352:2271-84.

171. Pittet LF, Verolet CM, McLin VA, et al. Multimodal safety assessment of measles-mumps-rubella vaccination after pediatric liver transplantation. Am J Transplant 2019;19:844-54.

172.Lal H, Cunningham AL, Godeaux O, et al. Efficacy of an adjuvanted herpes zoster subunit vaccine in older adults. $\mathrm{N}$ Engl J Med 2015;372:2087-96.

173. Biberfeld P, Kramarsky B, Salahuddin SZ, et al. Ultrastructural characterization of a new human B lymphotropic DNA virus (human herpesvirus 6) isolated from patients with lymphoproliferative disease. J Natl Cancer Inst 1987;79:933-41.

174. Okuno T, Takahashi K, Balachandra K, et al. Seroepidemiology of human herpesvirus 6 infection in normal children and adults. J Clin Microbiol 1989;27:651-3.

175. Troy SB, Blackburn BG, Yeom K, et al. Severe encephalomyelitis in an immunocompetent adult with chromosomally integrated human herpesvirus 6 and clinical response to treatment with foscarnet plus ganciclovir. Clin Infect Dis 2008;47:e93-6.

176. Nacheva EP, Ward KN, Brazma D, et al. Human herpesvirus 6 integrates within telomeric regions as evidenced by five different chromosomal sites. J Med Virol 2008;80:1952-8.

177. Singh N, Carrigan DR, Gayowski T, et al. Human herpesvirus-6 infection in liver transplant recipients: documentation of pathogenicity. Transplantation 1997;64:674-8.

178.Zerr DM, Gupta D, Huang ML, et al. Effect of antivirals on human herpesvirus 6 replication in hematopoietic stem cell transplant recipients. Clin Infect Dis 2002;34:309-17.

179. Singh N, Paterson DL. Encephalitis caused by human herpesvirus-6 in transplant recipients: relevance of a novel neurotropic virus. Transplantation 2000;69:2474-9.

180. Manuel O, Kumar D, Moussa G, et al. Lack of association between beta-herpesvirus infection and bronchiolitis obliterans syndrome in lung transplant recipients in the era of antiviral prophylaxis. Transplantation 2009;87:719-25.

181. Mesri EA, Cesarman E, Boshoff C. Kaposi's sarcoma and its associated herpesvirus. Nat Rev Cancer 2010;10:707-19.

182. Sampaio MS, Cho YW, Qazi Y, et al. Posttransplant malignancies in solid organ adult recipients: an analysis of the U.S. National Transplant Database. Transplantation 2012;94:990-8.

183. Dollard SC, Annambhotla P, Wong P, et al. Donor-derived human herpesvirus 8 and development of Kaposi sarcoma among 6 recipients of organs from donors with highrisk sexual and substance use behavior. Am J Transplant 2021;21:681-8.

184.Pietrosi G, Vizzini G, Pipitone L, et al. Primary and reactivated $\mathrm{HHV} 8$ infection and disease after liver transplantation: a prospective study. Am J Transplant 2011;11:2715-23.

185.Mularoni A, Gallo A, Riva G, et al. Successful Treatment of Kaposi Sarcoma-Associated Herpesvirus Inflammatory Cytokine Syndrome After Kidney-Liver Transplant: Correlations With the Human Herpesvirus 8 miRNome and Specific T Cell Response. Am J Transplant 2017;17:2963-9.

186. Delyon J, Rabate C, Euvrard S, et al. Management of Kaposi sarcoma after solid organ transplantation: A European retrospective study. J Am Acad Dermatol 2019;81:448-55.

187. Stallone G, Schena A, Infante B, et al. Sirolimus for Kaposi's sarcoma in renal-transplant recipients. N Engl J Med 2005;352:1317-23.

188. Lebbé C, Euvrard S, Barrou B, et al. Sirolimus conversion for patients with posttransplant Kaposi's sarcoma. Am J Transplant 2006;6:2164-8.

189. Smith CJ, Ryom L, Weber R, et al. Trends in underlying causes of death in people with HIV from 1999 to 2011 (D:A:D): a multicohort collaboration. Lancet 2014;384:241-8.

190.Kern RM, Seethamraju H, Blanc PD, et al. The feasibility of lung transplantation in HIV-seropositive patients. Ann Am Thorac Soc 2014;11:882-9.

191. Morabito V, Grossi P, Lombardini L, et al. Solid Organ Transplantation in HIV+ Recipients: Italian Experience. Transplant Proc 2016;48:424-30.

192. Gingo MR, Balasubramani GK, Kingsley L, et al. The impact of HAART on the respiratory complications of HIV infection: longitudinal trends in the MACS and WIHS cohorts. PLoS One 2013;8:e58812. 
193. Gingo MR, Morris A. Pathogenesis of HIV and the lung. Curr HIV/AIDS Rep 2013;10:42-50.

194. Doffman SR, Miller RF. Interstitial lung disease in HIV. Clin Chest Med 2013;34:293-306.

195. Crum NF, Riffenburgh RH, Wegner S, et al. Comparisons of causes of death and mortality rates among HIV-infected persons: analysis of the pre-, early, and late HAART (highly active antiretroviral therapy) eras. J Acquir Immune Defic Syndr 2006;41:194-200.

196. Blumberg EA, Rogers CC; American Society of Transplantation Infectious Diseases Community of Practice. Solid organ transplantation in the HIVinfected patient: Guidelines from the American Society of Transplantation Infectious Diseases Community of Practice. Clin Transplant 2019;33:e13499.

197. Muller E, Barday Z, Mendelson M, et al. HIV-positiveto-HIV-positive kidney transplantation--results at 3 to 5 years. N Engl J Med 2015;372:613-20.

198. Division of Viral Diseases, National Center for Immunization and Respiratory Diseases, Centers for Disease Control and Prevention. Updated norovirus outbreak management and disease prevention guidelines. MMWR Recomm Rep 2011;60:1-18.

199. de Wit MA, Koopmans MP, Kortbeek LM, et al. Etiology of gastroenteritis in sentinel general practices in the netherlands. Clin Infect Dis 2001;33:280-8.

200.Ahmed SM, Hall AJ, Robinson AE, et al. Global prevalence of norovirus in cases of gastroenteritis: a systematic review and meta-analysis. Lancet Infect Dis 2014;14:725-30.

201. Fankhauser RL, Monroe SS, Noel JS, et al. Epidemiologic and molecular trends of "Norwalk-like viruses" associated with outbreaks of gastroenteritis in the United States. J Infect Dis 2002;186:1-7.

202. Echenique IA, Penugonda S, Stosor V, et al. Diagnostic yields in solid organ transplant recipients admitted with diarrhea. Clin Infect Dis 2015;60:729-37.

203.Lopman BA, Reacher MH, Vipond IB, et al. Clinical manifestation of norovirus gastroenteritis in health care settings. Clin Infect Dis 2004;39:318-24.

204.Lee LY, Ladner DP, Ison MG. Norovirus infection in solid organ transplant recipients: a single-center retrospective study. Transpl Infect Dis 2016;18:932-8.

205.van Beek J, van der Eijk AA, Fraaij PL, et al. Chronic norovirus infection among solid organ recipients in a tertiary care hospital, the Netherlands, 2006-2014. Clin Microbiol Infect 2017;23:265.e9-e13.

206. Teunis PF, Sukhrie FH, Vennema H, et al. Shedding of norovirus in symptomatic and asymptomatic infections. Epidemiol Infect 2015;143:1710-7.

207. Wiersbitzky S, Schwarz TF, Bruns R, et al. Seroprevalence of human parvovirus B 19 antibodies (Sticker's disease/ erythema infectiosum) in the DRG population. Kinderarztl Prax 1990;58:185-9.

208. Eid AJ, Brown RA, Patel R, et al. Parvovirus B19 infection after transplantation: a review of 98 cases. Clin Infect Dis 2006;43:40-8.

209.Eid AJ, Ardura MI; AST Infectious Diseases Community of Practice. Human parvovirus B19 in solid organ transplantation: Guidelines from the American society of transplantation infectious diseases community of practice. Clin Transplant 2019;33:e13535.
Cite this article as: Munting A, Manuel O. Viral infections in lung transplantation. J Thorac Dis 2021;13(11):6673-6694. doi: $10.21037 /$ jtd-2021-24 